\title{
Jara Holliday, Oscar (2020) La Educación popular latinoamericana. Historia y claves éticas, políticas y pedagógicas, Ciudad Autónoma de Buenos Aires: El colectivo; Luján: EdUNLu, Editorial de la Universidad Nacional de Luján. 253 páginas, ISBN 978-987-47537-0-0
}

\author{
Amparo Tirado \\ tiradoamparo@gmail.com \\ Universidad Nacional de La Plata, Argentina
}

Cita sugerida: Tirado, A. (2020). [Revisión de La Educación popular latinoamericana. Historia y claves éticas, políticas y pedagógicas por O. Jara Holliday]. Archivos de Ciencias de la Educación, 14(18), e092. https://doi.org/10.24215/23468866e092

El libro que aquí se reseña fue escrito por Oscar Jara y condensa los aportes derivados de su tesis "Educación y cambio social, interpretación crítica de las contribuciones ético-políticas y pedagógicas de la educación popular latinoamericana" para la obtención del Doctorado Latinoamericano de Educación realizada en la Universidad de Costa Rica en el año 2017. Sin embargo, tanto el propio autor como sus colegas y lectores reconocen que su principal sustento y referencia es la extendida práctica de educación popular que Jara ha desarrollado a lo largo de su vida y a lo ancho de la Patria Grande.

Oscar Jara Holliday, de nacionalidad peruana y costarricense, es sociólogo y extensionista universitario; miembro fundador y actual director del Centro de Estudios y Publicaciones CEP Alforja así como también 
presidente del Consejo de Educación de Adultos de América Latina (CEAAL) entre los años 2012 y 2020. Tal como lo describe Carlos Rodriguez Brandão en el prefacio de este libro, además de ser un destacado estudioso académico, "es un educador popular de extensos senderos, largos pasos y esperanzados horizontes" un autor protagonista de los procesos que estudia.

Con vocación comprometida y militante, a lo largo de su trayectoria ha contribuido a la construcción de redes que vinculan distintas experiencias de educación popular y espacios de reflexión sobre la práctica educativa en América Latina. Ha dedicado parte de su trayectoria al desarrollo de métodos de sistematización de experiencias y a la formación metodológica de educadores populares a través de la red Alforja. Es autor de libros como Educación popular: la dimensión educativa de la acción política: reflexiones sobre la educación popular desde el contexto de la Revolución Sandinista ${ }^{2}$, La sistematización de experiencias, práctica y teoría para otros mundos posibles ${ }^{3}$, entre otros; y de múltiples publicaciones sobre educación popular, sistematización de experiencias, educación y cambio social.

En este libro en particular, Jara aborda la educación popular como fenómeno sociocultural y concepción educativa. En ese sentido, analiza e interpreta los fundamentos de la misma en búsqueda de los aportes teóricos y prácticos que puede realizar al debate educativo contemporáneo. Dicho trabajo lo realiza a la luz de una mirada histórica y un análisis crítico de las experiencias latinoamericanas de educación popular y de su vínculo con los distintos movimientos y procesos de cambio social que se han desarrollado en nuestra región. A su vez, su reflexión está orientada por la necesidad de construir un pensamiento latinoamericano y por la profunda convicción utópica y liberadora, intrínseca a esta concepción pedagógica, de que la educación es motor de la transformación social.

En el primer capítulo Educación Popular: ¿de qué educación hablamos?, el autor presenta el objetivo del trabajo y establece las coordenadas del mismo. Plantea la pregunta por el lugar de lo educativo en el contexto actual y particularmente de las prácticas educativas, objeto de su estudio. A partir de un balance crítico e integral del campo de la educación popular latinoamericana, identifica un área de vacancia en la producción referida a estudios sistemáticos sobre los fundamentos, alcances, límites y contribuciones de esta práctica educativa, que será punto de partida y encuadre de su trabajo.

El segundo capítulo, Cambio social y educación: vínculos, dilemas y desafios éticos, politicos y pedagógicos, profundiza en las dimensiones teóricas de análisis que orientan el trabajo, indicando una perspectiva epistemológica de la integralidad, la interrelación y la complejidad. Desde ese paradigma aborda las principales tensiones teórico-epistemológicas que fueron propias de su investigación: educación y cambio social; ética, educación y política; educación, instrucción y aprendizaje. A su vez, el autor profundiza en la pregunta por el lugar de lo educativo en la sociedad contemporánea, caracterizada por la celeridad de los cambios y las transformaciones sociales. En ese sentido, su análisis se inscribe en una perspectiva crítica que postula que es necesaria una educación que contribuya a transformar y humanizar el mundo a través de la formación de sujetos como agentes de cambio, en detrimento de una educación que se adapte a este nuevo mundo, donde predominan los discursos individualistas y neoliberales.

La estrategia teórico-metodológica y los desafíos de la investigación ocupan el centro del tercer capítulo: Producción de conocimiento desde las prácticas educativas: investigación y sistematización de experiencias. Se trata de un trabajo que se define a sí mismo como una propuesta militante de investigación cualitativa y reflexiva, una praxis educativa que pretende realizar una contribución a la mejora de las prácticas educativas. En esa línea, es un proceso en el cual la práctica es punto de partida y de llegada de la reflexión. Jara señala que su investigación tiene un irrenunciable compromiso con la acción y el paradigma de la educación popular, por lo cual los mencionados marcos epistémicos y metodológicos que se adoptaron son aquellos que se desprenden de la propia perspectiva crítica: retoma el método de la sistematización de experiencias y el trabajo colectivo y colaborativo con otros educadores y educadoras populares con los que dialoga cotidianamente.

Desde este marco teórico asentado y construido en los primeros capítulos, el cuarto capítulo, Panorama bistórico de la Educación Popular en América Latina, realiza un recorrido altamente significativo desde sus 
orígenes y hasta la actualidad (1959-2018). Este es el capítulo principal y el más extenso de este trabajo. Para ordenar dicho panorama el autor define cinco períodos delimitados por hitos que devienen del propio desarrollo de los movimientos políticos y sociales latinoamericanos a partir de la segunda mitad del siglo XX.

Desde una perspectiva pedagógica y política, cada hito señalado por Jara es significativo en la medida que inaugura un nuevo período en términos de la constante lucha por la emancipación y el cambio social en nuestra región, en los que se destaca el lugar que ocupa la cuestión educativa. Antes de caracterizar cada uno de ellos, dedica un apartado al desarrollo de los que considera antecedentes del término "educación popular". En el mismo, destaca las figuras de educadores y educadoras que, a lo largo del siglo XIX, se preocuparon por la instrucción pública de los países latinoamericanos. Durante este período, la problemática educativa surgió estrechamente vinculada a un proceso de cambio social como lo es la construcción republicana y democrática.

Los años que transcurrieron entre la Revolución Cubana iniciada en 1959 hasta el gobierno de la Unidad Popular en Chile en 1970 son considerados por el autor como el momento fundacional de la educación popular. A diferencia de los antecedentes del siglo XIX que asociaban educación popular con la expansión de la instrucción pública, este primer período se caracterizó por incorporar una perspectiva de clase asociada a procesos formativos de organizaciones políticas, sociales y culturales. Destaca el impacto del proceso revolucionario cubano a través de su iniciativa educativa de lucha contra el analfabetismo y los comienzos del desarrollo y la difusión de la pedagogía emancipadora y el pensamiento de Paulo Freire.

El segundo período comienza con la asunción del Gobierno de la Unidad Popular en Chile de la mano de Salvador Allende, en noviembre de 1970, y abarca la mayor parte de los años 70 hasta el triunfo de la Insurrección Popular Sandinista en Nicaragua, en 1979. Este es significado por Jara como un momento de afirmación de las propuestas de educación popular y del vínculo entre educación y política, ya que en esta década surgieron corrientes que entendían a la educación popular como una educación política que buscaba la concientización de las masas o la instrucción en teoría revolucionaria. A su vez, el autor analiza distintas cuestiones que caracterizaron a este tiempo histórico tales como el surgimiento de teorías epistemológicas populares y liberadoras como la investigación-acción participativa, el vínculo con los movimientos religiosos de liberación, los aportes de la obra de Carlos Rodriguez Brandão y las primeras instancias de encuentro e intercambio entre educadores y educadoras populares.

El tercer período retoma el triunfo de la Insurrección Popular Sandinista y se extiende hasta el levantamiento indígena zapatista mexicano en 1994. El autor lo describe como un período de proyección y expansión, a partir de la multiplicación de las experiencias de educación popular en toda la región latinoamericana, y del surgimiento de distintos fenómenos que abonaron a la consolidación del campo. Por estos años comenzaron a tener lugar los encuentros nacionales e internacionales de educadores y educadoras populares. A su vez, creció la producción y circulación de publicaciones escritas sobre el tema. Ambos fenómenos son destacados por Jara como instancias de intercambio, producción y sistematización de conocimiento específico. Por otra parte, también se subraya la importancia de la revolución sandinista como el primer proceso revolucionario en el cual la educación popular es tomada como eje estructurador de su proyecto y luego como política pública. En este marco de auge y consolidación de un campo en el que se debate, produce y discute alrededor de la educación de adultos y popular, surgen la red Alforja y el CEAAL.

El cuarto período abarca desde el levantamiento indígena zapatista hasta el I Foro Mundial en Porto Alegre en el año 2001. El mismo se encuentra signado por la crisis de los paradigmas de consenso de las décadas anteriores con el ingreso de las lógicas neoliberales a nivel global, lo cual condujo a un proceso que Jara nombra como la "refundamentación" del campo de la educación popular. En base a diversas críticas y cambios paradigmáticos, múltiples actores visibilizaron la necesidad de hacer resurgir un pensamiento crítico desde los países del Tercer Mundo que se amplíe en pos de incorporar nuevas realidades y sentidos de lo político, propias de aquel momento. Al mismo tiempo, Jara lo caracteriza como "la década de las cumbres" por las múltiples reuniones internacionales desarrolladas con el objetivo de discutir y planificar estrategias de desarrollo global. En las mismas, la cuestión educativa estaba fuertemente ligada al proyecto de desarrollo 
de los países y, desde el campo de la educación de adultos y la educación popular, fue posible realizar aportes a dichos debates. También hace mención a las propuestas educativas de distintos movimientos políticos y sociales de nuestra región como el levantamiento indígena zapatista en México y el Movimiento Sin Tierra (MST) en Brasil.

De este modo llegamos al quinto período, que abarca desde el I Foro Social Mundial "Otro mundo es posible" en Porto Alegre hasta el XIII Foro Social Mundial en Salvador de Bahía "Resistir es crear, resistir es transformar". Algunas de las cuestiones más relevantes del mismo tienen que ver con el vínculo que la educación popular establece con un nuevo sujeto social colectivo: los movimientos sociales. Así, surgen relaciones con distintos movimientos y corrientes del pensamiento crítico como los feminismos, los movimientos indigenistas del Buen Vivir, el ecologismo, y las distintas formas políticas de resistencia al neoliberalismo. Jara señala que esta apertura y vínculo con distintos tipos de movimientos populares logra que el campo de la educación popular comience a concebirse a sí mismo como un movimiento. Paralelamente, también se da un acercamiento con el ámbito universitario y académico desde el cual es tomada como un objeto de estudio, al mismo tiempo que se recuperan cuestiones de su perspectiva en la política académica.

El devenir del desarrollo histórico caracterizado en este libro por el autor, pone de manifiesto que el campo de la educación popular latinoamericana ha logrado desarrollarse y constituirse en constante vínculo con los procesos sociopolíticos y culturales de las últimas décadas, configurándose como un campo de referencia obligada para pensar el futuro de nuestra región. Otro aporte significativo que realiza este libro se encuentra en las últimas páginas del mismo, donde se incluye un anexo titulado "Cronología de eventos y publicaciones regulares de educación popular en América Latina (1970-2018)”. Dicha sistematización organiza temporalmente las publicaciones de prensa y encuentros, congresos, foros o eventos de los que se nutre este campo y abre una puerta para continuar construyendo conocimiento sobre el tema.

Una vez identificado el trayecto que siguió la educación popular latinoamericana en su historia, el autor dedica un último capítulo a la tarea de formular una interpretación crítica de las claves éticas, políticas y pedagógicas que orientan la misma con el objetivo de identificar aportes teóricos y prácticos a la relación que se establece entre la cuestión educativa y los procesos de cambio social. Realiza este análisis en torno a distintos ejes que le permiten obtener un balance del recorrido planteado en el capítulo anterior. En él se destacan las características constitutivas de los procesos de educación popular y contribuciones concretas que aportan o podrían aportar al debate educativo. Dichos aportes tienen que ver con la democratización del acceso a la educación, la posibilidad de pensar modelos educativos alternativos, la innovación y la reflexividad en la formación docente, la educación de adultos y el derecho al aprendizaje a lo largo de toda la vida, la posibilidad de pensar modelos alternativos de políticas públicas, el debate sobre la calidad de la educación, entre otros.

Finalmente, el epílogo presenta un resumen de las principales afirmaciones en las que se sustenta la posición desarrollada a lo largo del libro. De acuerdo con la conclusión a la que arriba el autor, podemos afirmar que los procesos de educación popular latinoamericanos afrontan el reto de vivir en constante construcción y reinvención, manteniendo su carácter liberador y emancipador y siendo motor del cambio social necesario de acuerdo a cada momento histórico, en cada época y en cada rincón de la Patria Grande.

Por otro lado, este libro ofrece interesantes análisis teóricos, metodológicos, políticos e históricos sobre las experiencias y procesos de una educación nacida en el seno de una región signada por profundas desigualdades, una educación que aborda la urgencia de transformar el orden social imperante, cuya trayectoria de expansión podemos descubrir a lo largo de estas páginas. Su lectura a la luz de un presente cargado de incertidumbres y profundización de dichas desigualdades, puede ayudar a quienes militamos por un mundo más justo, a formularnos nuevas y mejores preguntas para seguir avanzando hacia ese horizonte, recuperando la riqueza de las experiencias, de la organización y la lucha colectiva que caracteriza a la historia latinoamericana. A su vez también nos ofrece la reafirmación de la importancia de continuar investigando, creando y recreando prácticas de educación popular, y retomando sus principales aportes y reflexiones para que todas las prácticas educativas que llevamos adelante puedan ser más críticas, emancipatorias y populares. 


\section{Notas}

1 Rodriguez Brandão, Carlos (2018), Prefacio: Sobre una educación que se atrevió a ser "popular". Sobre una educación que se atrevió a ser "del oprimido", p.20. En Jara Holliday, Oscar (2020) La Educación popular latinoamericana. Historias y claves éticas, politicas y pedagógicas, Ciudad Autónoma de Buenos Aires: El colectivo; Luján: EdUNLu: Editorial de la Universidad Nacional de Luján.

2 Jara Holliday, Oscar. (1981). Educación Popular: La dimensión educativa de la acción politica - Reflexiones sobre la educación popular desde el contexto de la Revolución Popular Sandinista. Panamá: CEASPA.

3 Jara Holliday, Oscar. (2012). La Sistematización de Experiencias, práctica y teoria para otros mundos posibles. San José: CEP Alforja, CEAAL, Oxfam Intermón.

Recibido: 18 de septiembre 2020 